\title{
Figuras del Oriente en Mil mesetas y ¿Qué es la filosofia?: del I Ching y el pintor-poeta chino al pensamiento por figuras $y$ el devenir imperceptible
}

\section{Oriental figures in A Thousand Plateaus and What Is Philosophy?: from I Ching and the Chinese painter-poet to the thinking through figures and the becoming-imperceptible}

\author{
MATÍAS SOICH \\ CONICET - Facultad de Filosofía y Letras, Universidad de Buenos Aires \\ (Argentina)
}

Recibido: 25/03/2013 Aprobado: 19/04/13

\begin{abstract}
RESUMEN
Este trabajo desarrolla algunas «figuras del Oriente» presentes en la obra de Deleuze y Guattari: en primer lugar, los hexagramas del Libro de los Cambios como un caso límite entre el pensamiento por figuras y el pensamiento por conceptos, y entre sabiduría y filosofía; en segundo lugar, los paisajes «típicamente» orientales y occidentales que pueblan Mil mesetas y ¿Qué es la filosofía?; por último, la figura del pintor-poeta chino como realizador del devenir-imperceptible. El objetivo es explorar las resonancias conceptuales entre ambos autores y el pensamiento oriental, especialmente en cuanto a la articulación entre ontología y ética.
\end{abstract}

PALABRAS CLAVE

ORIENTE, CHINA, DELEUZE, GUATTARI, DEVENIR

(C) Contrastes. Revista Internacional de Filosofia, vol. XIX-Nº2 (2014), pp. 357-378. ISSN: 1136-4076

Departamento de Filosofía, Universidad de Málaga, Facultad de Filosofía y Letras

Campus de Teatinos, E-29071 Málaga (España) 


\begin{abstract}
This paper develops some «figures from the Orient» that appear in Deleuze and Guattari's work: firstly, the hexagrams from the Book of Changes, as a limit case in the distinctions between thinking through figures and thinking through concepts, and between wisdom and philosophy; secondly, the «typically» oriental and occidental landscapes that populate A Thousand Plateaus and What Is Philosophy?; and lastly, the Chinese painter-poet as achiever of a becoming-imperceptible. The aim is to explore the conceptual resonances between these authors' philosophy and oriental thought, especially regarding the articulation between ontology and ethics.
\end{abstract}

KEY WORDS

ORIENT, CHINA, DELEUZE, GUATTARI, BECOMING

EN UN TRABAJO PREVIO ${ }^{1}$ expuse algunas de las principales figuras orientales que aparecen en Mil mesetas explicitando sus vínculos con el pensamiento de Deleuze y Guattari. Dicha exposición se hallaba supeditada a un objetivo mayor: la búsqueda de un punto de resonancia común entre estos autores y el pensamiento oriental, particularmente el chino, a partir precisamente del análisis de los temas orientales presentes en Mil mesetas y ¿Qué es la filosofía? y, por otro lado, del análisis de las fuentes sinológicas allí citadas. En términos generales, el hilo conductor que recorre esta serie de «perturbadoras afinidades» reside en un conjunto de implicaciones prácticas, propias de una ontología marcada por su carácter relacional. Las figuras recogidas en aquel trabajo fueron, por un lado, los diversos juegos de mesa y artes marciales orientales que Deleuze y Guattari utilizan como ejemplos de los binomios aparato de Estado/máquina de guerra y espacio estriado/espacio liso; y, por otro lado, ciertas prácticas sexuales taoístas asociadas al cuerpo sin órganos. En este trabajo abordaré el resto de los temas y figuras relevados. En primer lugar, los hexagramas del Yijing (más conocido como I-Ching o Libro de los Cambios), presentados en ¿Qué es la filosofía? como un caso límite entre el pensamiento por figuras y el pensamiento por conceptos -cuestión estrechamente ligada, además, a la distinción entre sabiduría y filosofía; en segundo lugar, los diversos «paisajes» geo-filosóficos que, tanto en Mil mesetas como en ¿Qué es la filosofía?, Deleuze y Guattari asocian a Oriente y Occidente; y por último, la figura del pintor-poeta chino y sus procedimientos estilísticos, vinculada por los autores al devenir-imperceptible.

1 Soich, M., «Figuras del Oriente en Mil mesetas: del Tao y el go al cuerpo sin órganos y la máquina de guerra», artículo enviado para su publicación. 


\section{EL YiJING, ¿FILOSOFÍA O SABIDURÍA ORIENTAL? \\ PENSAR POR FIGURAS Y «ABSOLUTIZAR LA INMANENCIA»}

Las instancias orientales que aparecen en ¿Qué es la filosofía? se encuentran claramente enmarcadas en la pregunta que titula la obra y en el objeto delimitado por su respuesta: ¿cuál es el modo específico de pensar que define a la filosofía y cuál es su relación con otros modos?

Pensar es una forma particular de reaccionar ante el caos (lo real en continua variación): trazando un plano que lo intersecte y que, a la manera de una red, permita extraer de él ciertos movimientos. La filosofía, la ciencia y el arte son disciplinas que, en este sentido, piensan. De ese modo se distinguen tanto de la actividad no creativa con la que nos protegemos del caos (opinión) como de aquella en la que la creatividad es sometida a un plano suplementario que introduce la trascendencia: la religión o sabiduría, términos que Deleuze y Guattari parecen usar prácticamente como sinónimos. Específicamente entre la sabiduría/religión y la filosofía hay una diferencia de naturaleza y no de grado, que pasa por la manera en que se piensa y por la relación establecida con el plano. Es en la afirmación de esta diferencia donde encontramos una explícita distribución geográfica:

No se trataría sencillamente de una diferencia de nivel, como en una gradación, entre el filósofo y el sabio: el antiguo sabio procedente de Oriente piensa tal vez por Figura, mientras que el filósofo [griego] inventa y piensa el Concepto. ${ }^{2}$

La distribución parece dual y definitiva: «cada vez» que hay inmanencia, hay filosofía (y los filósofos que cultivan la inmanencia surgieron en el Occidente griego); «cada vez» que hay trascendencia, hay sabiduría (y los sabios vienen del Este $^{3}$ ). A partir de su medio particular, los griegos inventaron el concepto «para no caer de nuevo en las figuras de Oriente». ${ }^{4}$ Ahora bien, ien qué consiste pensar por figuras y en qué pensar por conceptos?

2 Deleuze, G. y Guattari, F., ¿Qué es la filosofía? (de aquí en más QEF), tr. T. Kauf. Barcelona: Anagrama, 2009, p. 9. Ya en Nietzsche y la filosofía Deleuze contraponía el filósofo a la figura oriental del sabio-sacerdote: «La filosofía es griega, en la medida en que es en Grecia donde alcanza su verdadera fuerza y sus finalidades, que no se confunden con las del Oriente-sacerdote, incluso cuando la sutiliza», Deleuze, G., Nietzsche y la filosofía, tr. C. Artal. Barcelona: Anagrama, 1986, pp. 13-14. Sin embargo, las connotaciones que Deleuze da allí a la palabra «sabio» están estrechamente ligadas al imaginario ascético y religioso del Oriente Medio antes que al del Extremo Oriente. Más adelante me referiré a otra figura del sabio (el taoísta, sheng ren) cuyas características no sólo lo alejan del «antiguo sabio procedente de [Medio] Oriente», sino que más bien lo aproximan al pensamiento deleuziano-guattariano de la inmanencia.

3 QEF, p. 47.

4 QEF, p. 103. 
La actividad de pensar siempre se lleva a cabo entre unos territorios y la tierra, a través de movimientos complementarios de (des)territorialización; por eso toda filosofía es una geo-filosofía. ${ }^{5}$ Tanto los Estados imperiales asiáticos como las ciudades griegas operan por desterritorialización -movimiento por el cual se transita del territorio a la tierra, esto es, por el cual se abandonan o deshacen las formaciones del plano de inmanencia. La desterritorialización puede ser de dos tipos: absoluta, cuando la tierra se conecta directamente con el plano de inmanencia del pensamiento, o relativa, cuando se relaciona de manera histórica con sus diversos territorios. A su vez, la desterritorialización relativa puede ser de inmanencia o de trascendencia. Los dos últimos subtipos no sólo distinguen a las ciudades griegas de los Estados orientales -aquellas proceden por desterritorialización relativa inmanente, estos por la trascendente -sino que además dan cuenta, respectivamente, de la génesis del pensamiento por conceptos y por figuras.

Si pensar es seccionar el caos mediante un plano, lo distintivo de la desterritorialización relativa trascendente es que introduce en este proceso un componente de verticalidad: un elemento separado del plano, por encima o sobre él. La comprensión es facilitada si tomamos estos términos espaciales literalmente: hay algo que baja, para orientarnos y traernos la Verdad, palabra divina, logos o revelación. Es la vertical celeste (ver Figura 1). La vertical «tiene que inclinarse o someterse a una especie de rotación para inscribirse en el plano del pensamiento-Naturaleza siempre inmanente: [...] se reclina sobre la horizontal del plano de pensamiento siguiendo una espiral». ${ }^{6}$ Según los autores, en este doble movimiento de rotación e inclinación la vertical proyecta algo sobre el plano de inmanencia: se trata de la Figura (ver Figuras 2 y 3). El pensamiento por figuras, propio de la sabiduría, se caracteriza entonces porque, en él, el plano de inmanencia es cubierto por proyecciones de lo trascendente. Las figuras introducen la trascendencia en el plano precisamente porque remiten a otra cosa (a la vertical). ${ }^{7}$

5 Para lo que sigue me baso en QEF, pp. 86-95.

6 QEF, p. 90.

7 «Cada vez que se interpreta la inmanencia como inmanente a Algo, se puede tener la seguridad de que este Algo reintroduce lo trascendente», QEF, p. 49. «La inmanencia absoluta es en sí misma: no es en algo, no está en otra cosa [...]. Sólo cuando la inmanencia no es inmanencia de otra cosa diferente de sí misma puede hablarse de plano de inmanencia», Deleuze, G., «La inmanencia: una vida...», en Dos regímenes de locos. Textos y entrevistas (1975-1995), tr. J. L. Pardo. Valencia: Pre-Textos, 2007, pp. 347-351, p. 348. 

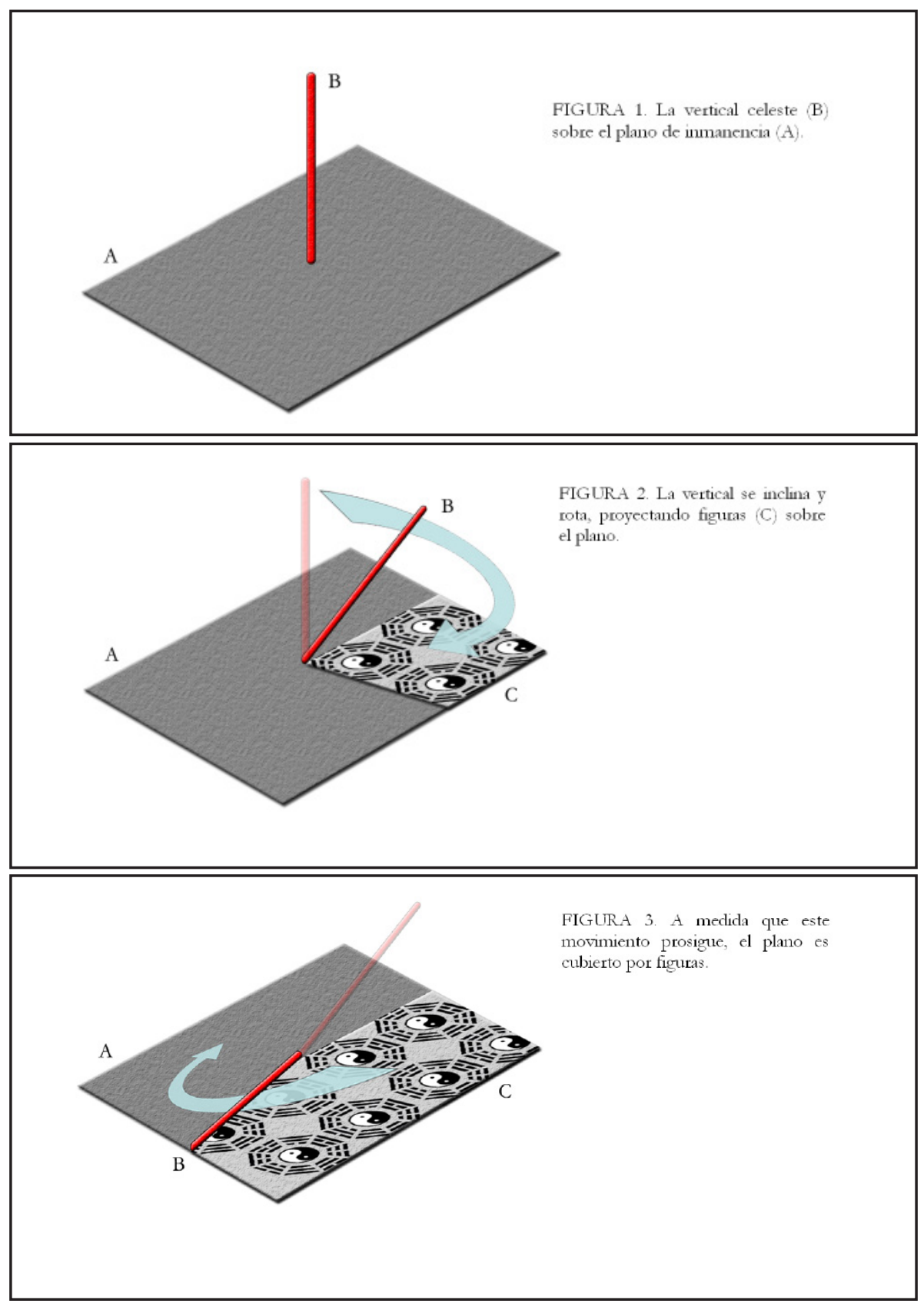
Por su parte, el pensamiento por conceptos se produce cuando la desterritorialización relativa se conjuga horizontalmente con la desterritorialización absoluta del plano. En lugar de subordinar la inmanencia a una vertical, el plano comunica entonces sus movimientos infinitos a la desterritorialización relativa, produciendo una duplicación de la inmanencia que da nacimiento al concepto. A diferencia de la figura, que por su origen es proyectiva, jerárquica y referencial, el concepto es conectivo, vecinal y consistente: su identidad no remite a algo «superior», sino que se define únicamente por las conexiones internas entre sus componentes y por sus conexiones externas con otros conceptos en el plano.

Ahora bien, a la hora de dar ejemplos concretos de figuras, nuestros autores apelan a culturas orientales. Entre los ejemplos sobresalen los hexagramas del antiguo clásico adivinatorio chino, el Yijing. Deleuze y Guattari definen los hexagramas como «combinaciones de trazos continuos y discontinuos que derivan unos de otros según los niveles de una espiral que representa el conjunto de los momentos bajo los cuales lo trascendente se inclina $\gg .{ }^{8}$ Esta complicada explicación puede y debe comprenderse apelando al esquema plano-vertical ya graficado.

¿Cómo es la relación entre conceptos y figuras? Los autores descartan antes que nada la simplificación que supone oponerlos como si se tratara de lo racional y lo irracional. Sucede más bien lo contrario: dado que ambos se vinculan con un mismo plano de inmanencia, entre conceptos y figuras «surgen perturbadoras afinidades $\gg .^{9}$ Para ejemplificar estas afinidades Deleuze y Guattari acuden nuevamente al pensamiento chino: los hexagramas del Yijing, recién definidos por su referencia a la vertical, ahora pueden ser considerados «conceptos» que surgen de la intersección de un plano (pensamiento-Naturaleza) caracterizado por dos movimientos diagramáticos infinitos (Yin y Yang). Sin embargo, esta afinidad sería tan sólo aparente; pues por apropiada que resulte la comparación, subsiste en ella una diferencia real. Proyectar sobre la inmanencia no es conjugarse con ella. La máxima relación entre figuras y conceptos se reduce entonces a una mayor o menor proximidad: las figuras «tienden hacia los conceptos hasta el punto de que se aproximan infinitamente a ellos», ${ }^{10}$ pero no son conceptos; mientras que los conceptos reproducen figuras en el instante en que subordinan la inmanencia a otra cosa. La conclusión tiene un aire ambivalente: «entre las figuras y los conceptos existe una diferencia de naturaleza, pero [también] todas las diferencias de grado posibles». ${ }^{11}$ Es importante señalar que esta relación aproximativa entre conceptos y figuras no es simétrica y que,

8 QEF, p. 90.

9 QEF, p. 92.

10 QEF, p. 93.

11 QEF, p. 94.

Contrastes vol. XIX-N² (2014) 
por lo tanto, en rigor no todas las diferencias de grado son posibles, o no son posibles en ambas direcciones. Las figuras pueden acercarse infinitamente a los conceptos, pero los conceptos no se acercan infinitamente a las figuras: un concepto reproduce figuras o no lo hace, conserva la inmanencia o la traiciona. Creo que la explicación de esta asimetría yace en el esquema mediante el cual Deleuze y Guattari ilustran la realización del pensamiento. De la figura al concepto: hay (o al menos es posible, pues no son taxativos al respecto) un momento en que la religión, para llegar al concepto, debe «renegar de sí misma». Identifico este momento con el límite ideal en que la vertical se ha inclinado tanto que deviene horizontal y desaparece, quedando sólo el plano (ver Figura 4). Antes de este punto límite Deleuze y Guattari admiten una progresión de la figura hacia el concepto producida por la inclinación gradual de la vertical.

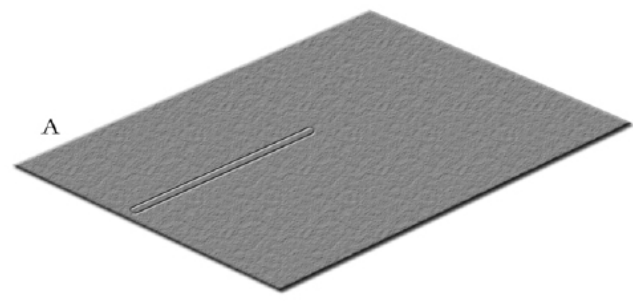

FIGURA 4. Caso limite "la religión reniega de si misma"): la vertical alcanza un máximo de inclinación y desaparece en el plano de immanencia.

Del concepto a la figura, sin embargo, la progresión es imposible. Pues en el instante mismo en que aparece la vertical, por mínima que sea su inclinación la situación ha cambiado por completo: el plano ya no existe «solo». La única gradualidad posible ahora corresponde nuevamente a las figuras, que se vuelven «cada vez más figura» a medida que la vertical se eleva alejándose del plano. La posibilidad de conceptos que se aproximen infinitamente a las figuras queda pues negada; sólo existen figuras que se aproximan a o se alejan de los conceptos.

Para referirse a este (imposible) contacto entre conceptos y figuras, Deleuze y Guattari utilizan la expresión «absolutización de la inmanencia», acuñada por el filósofo y sinólogo François Jullien. ${ }^{12}$ En su libro Procès ou Création

12 Nació en 1951 en Embrun, Francia. Cursó sus estudios en la École Normale Supérieure y en las Universidades de Shangai y Pekín. Doctor en Estudios de Extremo Oriente y en Letras, actualmente es profesor en la Universidad Paris VII y dirige el Instituto Marcel Granet. Algunas de sus obras, muchas de las cuales fueron traducidas al castellano, son: Lu Xun, Écriture et ré- 
(1989), Jullien afirma que el pensamiento chino, específicamente el de los letrados confucianos como Wang Fuzhi, se caracteriza por reducir el carácter trascendente del Cielo (concebido como un fondo de eficiencia absoluta y autorregulada) al de lo necesariamente «insondable» que este representa para la consciencia humana:

Esta perpetua inmanencia de la autorregulación [del Cielo], manifiesta en el seno de toda actualización concreta, desborda precisamente la consciencia humana por su carácter inagotable y no completamente identificable; y es este carácter de «insondable» el que constituye, entonces, la dimensión de «trascendencia» del gran proceso de la realidad. [.... Si bien desborda necesariamente la capacidad humana, el infinito del Proceso no es inconmensurable en relación a la consciencia que se tiene de él. La trascendencia en cuestión no es pues la de una otredad impensable [...] No hay dos órdenes sino uno solo, uno sirve de horizonte al otro (el Cielo en relación al hombre). Transcendencia eminentemente negativa, puesto que sólo representa entonces una «absolutización» de la inmanencia. ${ }^{13}$

Estas páginas están precisamente entre las citadas por Deleuze y Guattari en QEF. Según Jullien, el pensamiento chino no deja lugar para un más allá. La trascendencia del Cielo es siempre inmanente, «deviene totalmente inmanente a la consciencia del hombre». ${ }^{14}$ Esta inmanencia absolutizada cumple con la condición puesta por Deleuze para toda inmanencia auténtica: no devenir «inmanente a...», ser sólo inmanente respecto a sí misma. En lugar de que la inmanencia devenga inmanente a..., aquí más bien es la trascendencia la que deviene inmanente a la misma inmanencia. Por eso nuestros autores afirman que, en el mismo sentido en que Pascal y Kierkegaard buscaron lo trascendente en la inmanencia y terminaron «cargando de inmanencia misma» el plano, «cabría decir lo que François Jullien dice del pensamiento chino, la trascendencia es en él relativa y tan sólo representa ya una 'absolutización de la inmanencia'». ${ }^{15}$ Quizá sorprenda entonces cuando, unas páginas más adelante, al hablar sobre la relación aproximativa entre conceptos y figuras, Deleuze y

volution (1978), Éloge de la fadeur, A partir de la pensée et de l'esthétique de la Chine (1991), Figures de l'immanence: Pour une lecture philosophique du Yi king, le classique du changement (1993), Traité de l'efficacité (1997), Un Sage est sans idée, ou l'autre de la philosophie (1998), La chaine et la trame, Du canonique, de l'imaginaire et de l'ordre du texte en Chine (2004) y Nourrir sa vie, à l'écart du bonheur (2005).

13 Jullien, F., Procès ou Création. Une introduction à la pensée des lettrés chinois (de aquí en más PC). Paris: Éditions du Seuil, 1989, pp. 116-117, énfasis añadido. En todas las citas la traducción es mía.

14 PC, p. 229.

15 QEF, pp. 75-76. 
Guattari dan a la «absolutización de la inmanencia» un sentido opuesto al que le concedían páginas atrás:

Pero correspondencias de esta índole [por aproximación entre figuras y conceptos] no excluyen una frontera, incluso difícil de percibir. [...] Ciertamente, lo trascendente produce por proyección una «absolutización de la inmanencia», como ponía ya de manifiesto François Jullien en lo que al pensamiento chino se refiere. ${ }^{16}$

Como puede verse al comparar esta cita con la anterior, mientras que en aquella Deleuze y Guattari se referían a la «absolutización de la inmanencia» como una operación que (re)carga de inmanencia el plano, aquí la consideran en cambio una proyección de la vertical trascendente. Probablemente lo que motiva la desconfianza de nuestros autores sea el carácter de «horizonte» que Jullien, a pesar de insistir en la existencia de «un solo orden», le atribuye al Cielo de los chinos; así como la persistencia, en la lógica del Proceso, de lo «insondable» que puede connotar demasiado el carácter oculto del plano de organización. ${ }^{17}$ Sin embargo, a pesar de utilizar estas expresiones, Jullien trata la relación entre lo absoluto del Proceso y lo relativo de sus actualizaciones como una cuestión de escalas antes que de planos; lo insondable remite a nuestra imposibilidad de abarcar todo el devenir, antes que a una explicación que subordine el devenir a algo que está «en otra parte».18

Volviendo al Yijing, notamos que Jullien incurre en una ambigüedad significativamente similar a la de Deleuze y Guattari. Por una parte, en su lectura de Wang Fuzhi, Jullien presenta al hexagrama, en virtud de su exhaustividad, como «modelo reducido de toda la realidad», al conjunto de los 64 hexagramas como figuras que «imitan» completamente y desde adentro el dinamismo de la realidad, y al Yijing como libro que, a través del juego de la figuración, «va a la par» del proceso del universo y revela sus «misterios». ${ }^{19}$ Esta caracterización mueve a preguntarnos si no estamos finalmente ante el modelo, abarcador sólo a fuerza de ser esquemático, de un pensamiento por figuras que fija la realidad del cambio para remitirla a una instancia superior (por ejemplo, la Dualidad). En otras palabras: ¿no estamos ante la concepción clásica del libro como imagen del mundo, en cualquiera de sus variantes?. ${ }^{20}$ Sin embargo, por

16 QEF, p. 93, énfasis añadido.

17 Deleuze, G. y Guattari, F., Mil mesetas. Capitalismo y esquizofrenia (de aquí en más MM), tr. J. Vázquez Pérez. Valencia: Pre-Textos, 2006, p. 269.

18 PC, p. 117.

19 PC, pp. 196 ss.

$20 \mathrm{MM}, \mathrm{pp} .11-12$. En las formas arborificadas del libro, el pensamiento concibe un orden o sentido ocultos que están más allá del mundo y lo justifican. El libro se convierte en una mera representación y el pensamiento no logra pensar la multiplicidad, ya sea porque le impone un modelo trascendente que remite a lo Uno (y entonces podríamos preguntar: el Yijing, ¿ «Uno 
otra parte Jullien caracteriza al hexagrama como un concepto que, por ser «el más comprensivo que se pueda imaginar», es «el único concepto adecuado al proceso». Desde esta perspectiva, los hexagramas forman un sistema a la vez cerrado - como estructura fija del cambio -y abierto- dicha estructura sirve sólo como «diagrama» de la realidad. ${ }^{21}$

Para que la capacidad transformacional del sistema [del Yijing] pueda continuar ejerciéndose plenamente, es necesario guardarse de reducirlo a un modelo único (unívoco y predeterminado). Es decir que el sistema operatorio del hexagrama sólo tiene pertinencia si no está codificado. No hay patrón con el cual hacer coincidir de antemano la transformación. Porque, si se quiere que el pensamiento del proceso pueda dar cuenta efectivamente de la realidad, hace falta que este proceso en sí mismo no sea nunca concebido de modo estereotipado, sino que haga siempre un lugar en su interior a la diferencia, al desvío, a la novedad. [...] Para servir efectivamente de figura exploratoria del proceso, el sistema del hexagrama debe demostrar disponibilidad tanto como exhaustividad. ${ }^{22}$

Así pues, en términos de la alternativa planteada por Deleuze y Guattari entre modelo (instancia trascendente que organiza la realidad) y proceso (mo-

que deviene dos» en el Yin y el Yang?), ya sea porque, aunque simule contemplar la multiplicidad sin referirla a una unidad originaria, sigue haciéndola depender de una ley que limita sus combinaciones (y entonces podríamos preguntar: el Yijing, ¿sistema cerrado de combinaciones en función de una Unidad perdida?).

21 PC, pp. 195-196, 200. La noción de «diagrama» describe las operaciones del plano de consistencia: en QEF (pp. 53, 76) los movimientos diagramáticos son, precisamente, aquellos que el plano de inmanencia filosófico toma del caos por intermedio de los personajes conceptuales. En Foucault (1986) Deleuze define el diagrama como dimensión in-formal (materias no organizadas y funciones no finalizadas) de la máquina abstracta, definición presente ya en MM (Deleuze, G., Foucault, tr. J. Vázquez. Barcelona: Paidós, 1987, pp. 60, 63). Que Jullien hable del Yijing en términos de «diagrama/s» resulta pues un hecho sugestivo. Por un lado, los 64 hexagramas poseen rasgos que, según el Foucault, serían más propios de una estructura que de un diagrama, como el formar una combinatoria y un «ciclo de intercambio cerrado». Por otro lado, sin embargo, los movimientos diagramáticos del Yin y el Yang (QEF, p. 93) se actualizan en los hexagramas según un patrón inestable, no prefijado. En ese sentido los hexagramas serían como las formas estratificadas que, según dice Deleuze, si bien estabilizan el diagrama, al mismo tiempo le permiten conectarse con «otros estados inestables de diagrama, a través de los cuales las fuerzas prosiguen su devenir mutante» (Foucault, trad. cit., p. 115). Como afirmamos respecto de las formas arborificadas del libro, también aquí la cuestión es el carácter cerrado o abierto del Yijing: ¿combinatoria cerrada -y entonces no es diagrama, sino estructura-o apertura diagramática hacia «un futuro con el que nada se acaba, puesto que nada ha comenzado, sino que todo se metamorfosea»? (Foucault, trad. cit., p. 119).

22 PC, pp. 196-199, énfasis añadido. 
vimientos en el plano único e inmanente de lo real23), Jullien da del Yijing una interpretación ambivalente: un modelo cuyo funcionamiento sólo es posible en tanto es inseparable del proceso que expresa, sin el cual no tendría sentido alguno; una estructura cerrada y completa, pero que no tiene ninguna operatividad si no conserva una disponibilidad esencial y una apertura a sentidos nuevos. De igual forma, en términos de la alternativa entre figuras y conceptos, Jullien lee el Yijing como una instancia extraña, no intermedia pero sí fronteriza: una figura exploratoria del proceso que proyecta, sobre la inmanencia de las mutaciones, el patrón móvil de una «trascendencia» que no es más que la inmanencia absolutizada.

Por último, la relación entre figuras, conceptos y plano de inmanencia aparece estrechamente ligada a la pregunta por la posibilidad de una filosofía oriental. A diferencia de las respuestas dadas por filósofos anteriores, ${ }^{24}$ la de Deleuze y Guattari comienza siendo explícitamente afirmativa. Sin embargo, subsisten en ella las comillas: «¿Cabe hablar de una 'filosofía' china, hindú, judía, islámica? Sí, en la medida que pensar se hace sobre un plano de inmanencia, en el que pueden morar tanto figuras como conceptos». ${ }^{25} \mathrm{Si}$ Deleuze y Guattari escriben «'filosofía" oriental» entre comillas es porque afirman que efectivamente Oriente piensa, pero que no lo hace por conceptos. ${ }^{26} \mathrm{La}$ existencia de sabidurías orientales mostraría que el plano de inmanencia de la filosofía era en realidad pre-filosófico: dado que puede ser llenado tanto por conceptos como por figuras, «en sí mismo no tenía como destino inevitable una creación de concepto o una formación filosófica». ${ }^{27} \mathrm{Si}$ bien es cierto que sólo se vuelve estrictamente filosófico cuando es ocupado por conceptos, gracias a las figuras el plano mantiene una «relación filosófica con la no-filosofía». Esto implica, a su vez, que las «sabidurías orientales» mantienen una relación no-filosófica con el plano de inmanencia filosófico, aproximándose a él sin llegar a tocarlo y mostrando que los conceptos no eran sus únicos habitantes por derecho. Por todo

23 Este distinción entre modelo y proceso se encuentra desarrollada de manera dispersa a lo largo de MM; v. especialmente la Introducción, pp. 17 ss., y la meseta décima, pp. 287 ss.

24 En torno a la cuestión del origen (griego) de la filosofía, atada directamente a la de la posibilidad de una filosofía oriental, Deleuze y Guattari escogen como interlocutores a Hegel y Heidegger: para el primero, Oriente estaría «antes» que la filosofía, porque pensó, pero no llegó a relacionar el objeto con el sujeto; para el segundo estaría «al lado», porque pensó, pero no pensó el Ser. V. QEF, pp. 95-96.

25 QEF, p. 94, énfasis añadido.

26 Pareciera como si, después de todo, esta respuesta coincidiese con las de Hegel y Heidegger en el espíritu de un «pero... » común a todas. ¿Involuntaria renovación del eurocentrismo en Deleuze y Guattari? V. Jullien, F., Un sabio no tiene ideas o el otro de la filosofía, tr. A.-H. Suárez Girard. Madrid: Siruela, 2001, pp. 84 ss.

27 QEF, p. 94. 
ello, podríamos decir que filosofía y sabiduría se encuentran en una situación de íntima exterioridad: es justamente porque se aparta de ellas que la figura puede mostrarnos las condiciones de posibilidad del concepto. En el mismo sentido, los hexagramas del Yijing serían para estos autores cuasi-conceptos, producidos por una vertical del pensamiento que se aparta sutilmente del plano.

\section{ORIENTE y OcCidente: LA GeOgRafía Y el PAISAJE}

Nuestro recorrido continúa con algunas imágenes signadas por su orientación según dos de los puntos cardinales: el oeste y el este, y por las formaciones culturales correspondientes: Occidente y Oriente. Por esta vía, el texto de MM permite extraer una nutrida paisajística. Yendo hacia el Oeste encontramos el reino de los árboles y las raíces: bosques y campos, desmontados los unos y sembrados los otros en función de una economía real, señorial o familiar, pero siempre signada por un principio de organización productiva; ${ }^{28}$ casas, corrales con ganado, jardines, fortalezas y catedrales. Hacia el Este, en cambio, grandes espacios abiertos, huertas, estepas y desiertos, pequeños grupos de cultivadores y grandes tribus nómadas: el reino del rizoma. Aquí la circulación de las aguas es respetada, los puentes y los canales no bloquean los ríos, mientras que en Occidente se construyen diques y acequias. Hacia el desierto de Oriente se huye como hacia un punto de fuga; tribus de tuaregs, de mongoles y de esquimales recorren desiertos de arena y de hielo, pero también de agua (el mar, surcado por nómadas barcos piratas). Pero al recorrer estos paisajes surgen inevitablemente las preguntas: ¿acaso las grandes extensiones heladas no remiten al Sur y el Norte, antes que al Este? ¿Acaso los mares no ocupan todo el globo? La geografía como sucesión de postales («esta es de Oriente, esta de Occidente») se muestra entonces insuficiente, y comenzamos a ver que las denominaciones «Este» $\mathrm{y}$ «Oeste» encierran motivos no sólo geográficos, sino también dinámicos. Los desiertos y las estepas, los campos y los bosques, lejos de caracterizarse únicamente por una ubicación geográfica definen además modos de habitar el espacio y tipos de pobladores. Por ejemplo el nómada, habitante de los desiertos, que subordina las detenciones y los acampes al movimiento libre del trayecto. El nómada «se aferra a ese espacio liso en el que el bosque recula, en el que la estepa o el desierto crecen», ${ }^{29}$ un espacio que le permite desplazarse sin echar raíces. El sedentario, en cambio, divide y reparte la tierra, siembra cimientos para construir edificios, y recorre sus trayectos en función de metas y puntos de partida.

En tanto geografía y paisaje, Oriente y Occidente representan sin embargo algo más que modos de habitar el espacio. Pues además de en la tierra, los

28 MM, p. 23.

29 MM, p. 384.

Contrastes vol. XIX-N² (2014) 
árboles y los rizomas crecen sobre todo en el pensamiento. ${ }^{30} \mathrm{Al}$ geográfico y al dinámico se suma entonces un tercer aspecto, el conceptual. Los dos paisajes y sus modos de habitar se conjugan entonces en sendos modelos de pensamiento y vida: residir en el Oeste, en los bosques de la trascendencia, o viajar por el Este, surcando los desiertos inmanentes: «¿No existe en Oriente [...] una especie de modelo rizomático que se opone desde todos los puntos de vista al modelo occidental del árbol?».31

El planteamiento de estos dos modelos geográfico-conceptuales contrapuestos es lo que permite a Deleuze y Guattari afirmar, en relación con la música, que «al plan organizativo transcendente de una música occidental [...] se opone un plan de consistencia inmanente de la música oriental», ${ }^{32}$ o que Estados Unidos ha situado su Oriente (su línea de fuga) en el Oeste, tierra de experimentación y de viajes inmóviles. ${ }^{33}$ De este modo se revela a la vez la separación y el entrecruzamiento entre ambos motivos, el del modelo de pensamiento (por ejemplo Oriente, con sus rasgos particulares: apertura hacia líneas de fuga, devenir, etc.) y el de la locación geográfica (por ejemplo, el Oeste del mapa norteamericano). ¿Será casualidad que el Oriente del pensamiento estadounidense se encuentre justamente en su oeste geográfico, allí donde se extienden sus desiertos? ¿Es acertado postular una correspondencia tal entre el pensamiento y las coordenadas y contornos de la tierra?

Nuestros autores se apresuran a precavernos: «Por supuesto, resulta muy fácil presentar un Oriente inmanente y rizomático [...] estas distribuciones geográficas no nos llevan por el buen camino», ${ }^{34}$ dando a entender que la existencia de los modelos «Oriente»y «Occidente» no debe movernos a tomar la brújula para hallar correspondencias necesarias. En este sentido, aunque la trascendencia siga siendo una «enfermedad específicamente europea», ${ }^{35}$ ello no quita que también el Este cargue el plano de inmanencia con sus propias organizaciones. Deleuze y Guattari citan diversas investigaciones sobre los imperios de la Antigüedad para mostrar que Oriente, la tierra del rizoma, tiene sus propias formaciones despóticas. Las recurrentes menciones a imperios orientales (que ya jugaban un papel importante en El Anti-Edipo) ilustran en MM la relación del Estado con la máquina de guerra y el espacio liso: se habla entonces de líneas asirias, egipcias, chinas, de estriaje imperial. ${ }^{36}$ Los estudios

30 MM, p. 20.

31 MM, p. 23, énfasis añadido.

32 MM, p. 273.

33 MM, pp. 23-24, 32 n. 17.

34 MM, p. 23.

35 Ibidem.

36 MM, p. 503. Un año después de la publicación de QEF, Guattari señalaba nuevamente que pueden encontrarse «recortes de trascendencia» en los imperios egipcios, mesopotámicos y 
citados sugieren que la forma-Estado surgió eminentemente en Asia y África al darse ciertas condiciones diferentes de las del mundo griego. Ante los grandes espacios lisos y la circulación libre de flujos descodificados, el Estado oriental habría surgido como un aparato de sobrecodificación y estriaje que supone la acumulación de reservas agrícolas y el consumo de su excedente mediante la organización de cuerpos militares, burocráticos y de artesanos. En ese entorno fuertemente jerarquizado, la figura colectiva del Excluido emerge como un flujo producido necesariamente por el aparato estatal y que evade sus redes: así, un flujo de artesanos y comerciantes pasa desde los imperios orientales hacia el «medio de inmanencia» egeo, en donde encuentra una mayor libertad de movimiento. Las respectivas situaciones a uno y otro lado del Cáucaso determinan de ese modo que «los mismos flujos que están sobrecodificados en Oriente tienden a descodificarse en Europa». Gracias a este pasaje de flujos, las polis griegas se habrían beneficiado de las grandes reservas orientales sin tener que adoptar ellas mismas el modelo imperial. ${ }^{37}$

Como ya dijimos, en QEF este escenario será explicado a partir de la relación que une al pensamiento con el movimiento de los territorios y la tierra. Allí se dice que tanto a los Estados orientales como a las ciudades griegas les corresponde un movimiento de desterritorialización relativa; mientras que los primeros efectúan una desterritorialización de trascendencia vertical, la desterritorialización efectuada por las segundas permite la creación de un medio de inmanencia horizontal y de circulación libre. Mientras que en Oriente el déspota marca el límite celeste e impone un férreo control sobre los flujos, «únicamente Occidente extiende y propaga sus centros de inmanencia»; el medio griego, en lugar de recibirlos desde arriba, interioriza y expande sus límites socioeconómicos ${ }^{38}$ Respecto de los paisajes conceptuales que acabamos de ver, estas conjunciones entre la tierra y el plano del pensamiento constituyen pues una disrupción: es en el Occidente «arborizado», «enfermo de trascendencia» de $\mathrm{MM}$ donde surge el medio que da origen al pensamiento por conceptos, mientras que en el Oriente «rizomático» parece primar la conservación de un pensamiento trascendente por figuras.

chinos. Guattari, F., Caosmosis, tr. I. Agoff. Buenos Aires: Manantial, 2010, p. 129.

$37 \mathrm{MM}$, p. 456. Al exponer la historia de la filosofía china, Feng Youlan contrapone de igual modo al pueblo comerciante y marítimo de las ciudades griegas, en donde prima la movilidad (de monedas, productos, idiomas, etc.), al sistema «familiar-estadual» chino, donde el Estado es concebido jerárquicamente en términos de familia y hay una mayor resistencia a los cambios. Feng Youlan, Breve historia de la filosofía china. Beijing: Ediciones en Lenguas Extranjeras, 1989, pp. 43-45.

38 QEF, p. 98. V. también pp. 86-88. 


\section{PintURA Y POESÍA CHINAS: DEVENIR-IMPERCEPTIBLE}

Sobriedad, despersonalización, devenir: prácticas vitales para todo tipo de pensadores y artistas. Si bien se encuentra desarrollado en la décima meseta de $\mathrm{MM}$, este tema reaparece a lo largo de dicha obra y también es mencionado en QEF.

Al igual que el de cuerpo sin órganos, el concepto de devenir es eminentemente práctico. Su primera definición en MM es por la negativa: devenir no es imitar, ni realizar una identificación entre dos cosas; no es pasar por los términos de una serie, hacer corresponder analógicamente relaciones o evolucionar por filiación. ${ }^{39}$ De estas definiciones negativas, formuladas contra las interpretaciones clásicas del devenir, Deleuze y Guattari enfatizan especialmente la que lo distingue de la imitación y la semejanza. Un devenir incluye al menos dos elementos que no actúan como modelo y como copia, sino que devienen en bloque, bajo una relación asimétrica. No se puede devenir algo sin que ese algo devenga a su vez otra cosa: cuando un pintor pinta un pájaro no lo imita ni lo reproduce, sino que él mismo deviene pájaro, a la vez que el pájaro deviene color y línea. ${ }^{40} \mathrm{La}$ imitación y la semejanza pueden estar incluidas en un devenir, pero no lo definen: el cuadro, el pájaro y el pintor pueden parecerse, pero constatando parecidos no aprenderemos mucho sobre el devenir-pájaro del pintor.

Estas definiciones por la negativa muestran que el verbo «devenir» es irreductible a otros verbos, que expresa una realidad por derecho propio y exige, pues, una definición positiva. ${ }^{41}$ En términos generales, podemos entender «devenir» como el movimiento de transformación constante de las multiplicidades que pueblan el plano de inmanencia. Si bien todo devenir es molecular y minoritario, implica una «extracción de partículas» a partir de una base molar, estratificada (sujetos, órganos y/o funciones ${ }^{42}$ ). Así, a partir de la forma molar «hombre», mayoritaria por excelencia, pueden producirse el devenir-mujer, el devenir-niño, el devenir-animal, el devenir-imperceptible... ${ }^{43}$

Este último, que Deleuze y Guattari denominan «final inmanente» y «fórmula cósmica» del devenir, se identifica con el punto en que la velocidad de los procesos de individuación los vuelve indiscernibles de los movimientos mismos del plano. Devenir-imperceptible implica, al menos, tres aspectos:

1. «Ser como todo el mundo»: pasar desapercibido, no ser ya reconocido tras haber deshecho el propio rostro; eliminar todo lo superfluo para poder

39 MM, p. 245.

40 MM, p. 303.

41 MM, pp. 244-245.

42 MM, p. 275.

43 MM, p. 291. 
convertirse en una línea abstracta, circular entre las cosas y conectarse con otras líneas.

2. «Crear un mundo»: a partir de estas conexiones componer, entre sí y con las que ya se tenía, nuevas potencias, afectos y líneas, en un proceso que implica experimentación y selección, conservación y descarte.

3. «Hacer de todo el mundo un devenir»: el mundo así compuesto es «necesariamente comunicante», él mismo deviene, está compuesto por velocidades y conexiones entre individuos del tipo haecceidad, en lugar de relaciones entre propiedades, sustancias y sujetos. ${ }^{44}$

Por su cercanía con el plan de consistencia, devenir-imperceptible conlleva la potencia de deshacer las estratificaciones que bloquean el cuerpo sin órganos. Ser como todo el mundo, crear un mundo, hacer de todo el mundo un devenir, exigen debilitar los tres estratos, ejerciendo así lo que Deleuze y Guattari llaman «las tres virtudes»: Imperceptible (lo anorgánico: desarticular el cuerpo en lugar de someterlo al organismo), Indiscernible (lo asignificante: experimentar en lugar de interpretar) e Impersonal (lo asubjetivo: ser un nómada en lugar de un sujeto fijado ${ }^{45}$. Todo un nuevo modo de vida. Y sin embargo, ¿quién es capaz de practicar las tres virtudes? ¿Quién puede desmontar sus estratos y transformarse en una línea abstracta sin morir en el intento? Ciertos ejemplos privilegiados provienen, precisamente, de Oriente.

«Pasar la pared [del estrato significante], quizá lo hayan conseguido los chinos, pero ¿a qué precio? Al precio de un devenir-animal, de un devenir-flor o roca, y, todavía más, de un extraño devenir-imperceptible». ${ }^{46}$ ¿Por qué los chinos? Consideremos el ideario taoísta: como filosofía y como práctica, constituye un elogio de la sobriedad y simplicidad de lo imperceptible. El Tao, su principio cosmológico y ético, es identificado con el No-ser $(w u)$ y es descrito entonces como insípido, invisible e inaudible: una nada. Sin embargo dicha nada no es sinónimo de una carencia; por el contrario, designa la plenitud de lo relacional. Es precisamente porque (no) es nada, porque está vacío, que el Tao penetra todas las cosas y las hace ser y funcionar:

El Tao es vacío, más su eficiencia nunca se agota. (Laozi, cap. 4$){ }^{47}$

Treinta radios convergen en el cubo de una rueda, y merced a su vacío, el carro cumple su misión. Modelando la arcilla se hacen las vasijas, y merced a su vacío,

44 MM, pp. 280 ss.

45 Ibidem.

46 MM, p. 191.

47 El Laozi, más conocido como Tao Te King, es el clásico fundamental del taoísmo filosófico chino. Todas las citas en este trabajo pertenecen a: Preciado Idoeta, I. (ed. y trad.), Tao Te Ching. Los libros del Tao. Madrid: Trotta, 2006. 
Figuras del Oriente en Mil mesetas...

las vasijas de arcilla cumplen su misión. [...] Y así, del ser depende el uso, y del no-ser [wu], que cumpla su misión. (Laozi, cap. 11)

Los mismos principios valen para el «hombre sabio» (sheng ren), aquel que «ha obtenido» y practica el Tao. El sabio está en conexión con el Tao precisamente porque puede «vaciarse», desprenderse de sus conocimientos y pretensiones, así como de todo otro tipo de rigideces (estratificaciones). No se aferra ni siquiera a su propia sabiduría, y así experimenta la movilidad sin fin del Vacío. Su proceder es claramente sustractivo:

El espacio entre el Cielo y la Tierra, ¡cómo se asemeja a un fuelle! Vacío y nunca se agota; cuanto más se mueve, más sale de él. Los muchos decretos acarrean un pronto desastre; más vale conservar un reposado vacío. (Laozi, cap. 5)

Entregarse al estudio es crecer día a día; practicar el Tao es menguar día a día; menguar y menguar hasta llegar al no-actuar, no se actúa, más nada hay que se deje de hacer. (Laozi, cap. 48)

Gracias a esta sustracción creadora el taoísta ingresa en un devenir-imperceptible que lo hace ser como todo el mundo. Aparenta ser un hombre ordinario que no llama la atención de nadie, cuya descripción se confunde con la de un paisaje deshabitado:

Vacilantes, como quien cruza un río en pleno invierno; precavidos, como quien teme a todos sus vecinos; discretos, como huésped; frágiles, como el hielo a punto de fundirse; honestos y sencillos, como un leño; amplios, como un valle; indistintos, cual turbias aguas; tranquilos, como el mar profundo; naturalmente elegantes, como si no tuvieran límites. (Laozi, cap. 15)

Por otra parte, la virtud que Deleuze y Guattari llaman Imperceptible es particularmente estimada por los taoístas en su aspecto de des-organización del cuerpo. Por las páginas del segundo clásico taoísta, el Zhuangzi (más conocido como Libro de Chuang-Tsé), pulula toda una cohorte de deformes e inválidos que conocen muy bien el valor de lo anorgánico. Si el organismo le impone al cuerpo sin órganos «trascendencias organizadas para extraer de él un trabajo útil», ${ }^{48}$ entonces el Zhuangzi hace el elogio de la inutilidad: allí leemos que el árbol bien formado es aserrado para fabricar muebles, el buey sin mácula es sacrificado a los dioses, el erudito reclutado en la corte. Sólo sobreviven los feos, los manchados, los desorganizados, gracias a la utilidad vital de lo inútil.

MM, p. 164. 
El lisiado y contrahecho Shu tenía metido el mentón en el ombligo. Los hombros se le elevaban más altos que su cabeza. Su giba apuntaba al cielo. La región lumbar (la de las cinco vísceras), quedaba arriba. Las nalgas le servían de costados. Con remendar y lavar vestidos viejos sacaba lo suficiente para comer. Además, aventando arroz sacaba para alimentar diez personas. Cuando había reclutamiento de quintos allí andaba el contrahecho entre ellos, arremangados sus brazos (sin miedo a que lo cogieran). Por enfermo crónico, el contrahecho no estaba obligado a contribuir a los trabajos públicos. En cambio, cuando se distribuía grano para los enfermos, recibía tres chung de grano y diez cargas de leña. Este, sólo por ser contrahecho de cuerpo, podía sacar para vivir y llegar tranquilamente hasta el fin natural de sus días. ¿Cuánto más si hubiera sido lisiado en la virtud?. ${ }^{49}$

Practicando esta virtud, el sabio taoísta goza de una conexión vital que le permite «hacer de todo el mundo un devenir»: se mueve sin daño entre las cosas, en un verdadero viaje inmóvil. Ha logrado la difícil tarea de devenirimperceptible y, por eso, está a salvo de los peligros de la molaridad. «El rinoceronte no halla en él lugar donde cornear ni el tigre donde clavar sus garras, ni las armas donde aplicar su filo. ¿Cuál es la causa de ello? Porque no hay en él lugar para la muerte» (Laozi, cap. 50).

Lo que el sabio efectúa de este modo no es sino la apertura a líneas de fuga positivas y vitales, el trazado de un territorio secreto. «Ya nada puede pasar, ni haber pasado. Ya nadie puede hacer nada por mí ni contra mí. Mis territorios están fuera de alcance, y no porque sean imaginarios, al contrario: porque estoy trazándolos»». ${ }^{50} \mathrm{El}$ taoísta es un nómada: no calcula su trayecto en función de paradas preestablecidas, sino que subordina las detenciones a las necesidades del movimiento mismo. Traza sus territorios circulando entre las cosas, una operación en apariencia sencilla, pero imposible desde que se pretende hacer de ella objeto de cálculo o destreza.

«Pasar la pared, quizá lo hayan conseguido los chinos». Este sujeto colectivo se concretiza en MM en la figura del pintor-poeta, cuyos procedimientos remarcan que el devenir-imperceptible no tiene nada que ver con la imitación y la semejanza. «Ni imitativo ni estructural, sino cósmico», el pintor-poeta aprehende los movimientos moleculares de la naturaleza en lugar de copiar sus formas estáticas. Deleuze y Guattari citan L'écriture poétique chinoise, donde el sinólogo François Cheng «muestra cómo el poeta no persigue la semejanza, ni tampoco calcula 'proporciones geométricas'. Retiene, sólo extrae las líneas y los movimientos esenciales de la naturaleza, sólo utiliza 'trazos' ininterrumpi-

49 Elorduy, C. (trad.), Chuang-Tzu. Literato, filósofo y místico taoista. Caracas: Monte Ávila Editores, 1972, p. 34.

50 MM, p. 204. 
dos o sobreimpuestos». ${ }^{51}$ Según Cheng, desde un punto de vista «propiamente pictórico» el trazo del pincel no apunta al contorno de las formas, sino a captar las «líneas internas» (li) de la cosas y los soplos (qi) que las animan:

Montaña, roca, bambú, árbol, ondas en el agua, brumas y nubes, todas estas cosas de la naturaleza no tienen una forma fija; en cambio, cada una de ellas tiene una línea interna constante [li]. Esta es la que debe guiar [a través del trazo] el espíritu del pintor. ${ }^{52}$

Si los trazos del pintor permiten ingresar en un devenir cósmico e imperceptible, es precisamente porque la pintura china tiene como precepto la sobriedad en la ejecución. Deleuze y Guattari insisten con una idea: la mayor riqueza en los efectos se logra por una máxima simplicidad en los medios, a fuerza de deshacer, por eliminaciones y sustracciones creadoras: «Lo múltiple hay que hacerlo, pero no añadiendo constantemente una dimensión superior, sino, al contrario, de la forma más simple, a fuerza de sobriedad». ${ }^{53}$

En el lenguaje pictórico chino, «sobriedad» significa introducir en el lienzo una cantidad suficiente de Vacío - entendido literalmente como espacio sin pintar, pero también y sobre todo en sentido ontológico (como No-ser, wu). El Vacío asegura la eficacia de los componentes pictóricos, la circulación de los soplos vitales en el lienzo y el devenir conjunto del cuadro, el espectador y la Naturaleza. Cheng recoge numerosos testimonios de pintores y teóricos del arte chinos sobre la importancia del Vacío y la sobriedad; en QEF Deleuze y Guattari reproducen uno de ellos. A propósito del papel del vacío en la conservación de la obra de arte (donde todo «se conserva en el vacío conservándose a sí mismo») los autores parafrasean al pintor Huang Binhong, quien enuncia un viejo proverbio: el lienzo debe contener «suficientes vacíos para que puedan retozar en ellos unos caballos». ${ }^{54} \mathrm{El}$ testimonio tal como figura en el libro de Cheng vincula el vacío pictórico con la idea de disponibilidad: un cuadro «ganado» es aquel que permanece disponible para un devenir.

51 MM, p. 281. Cheng Baoyi (François Cheng), académico, escritor, calígrafo y traductor. Autor de numerosas obras sobre la estética y el pensamiento chinos. Nació en 1929 en Nanchang, China. Completó sus estudios en la Universidad de Nanking y viajó a Francia en 1948, nacionalizándose francés en 1971. Doctor honoris causa por la Universidad de Bérgamo, Italia, y por el Instituto Católico de París, en 2002 fue electo miembro de la Academia Francesa. Algunas de sus obras son: L'Espace du rêve: mille ans de peinture chinoise (1980), Shitao: la saveur du monde (1998), Le livre du Vide médian (2004), Cinq méditations sur la beauté (2006), Un cheminement vers la vie ouverte (2009) y Quand reviennent les âmes errantes (2012).

52 Cheng, F., Vide et plein. Le langage pictural chinois. Paris: Éditions du Seuil, 1991, p. 75, mi traducción (cita del pintor Su Dongpo).

53 MM, p. 12.

54 QEF, p. 166. 
Pintar un cuadro es como jugar al ajedrez (al juego del go). Uno se esfuerza por disponer sobre el tablero los «puntos disponibles». Cuantos más de estos se tiene, más seguro se está de ganar. En un cuadro, estos puntos disponibles son los vacíos [...] En alusión a esto los Antiguos decían: El espacio puede ser llenado a tal punto que el aire no pase más, [y] a la vez contener vacíos tales que los caballos puedan brincar en él cómodamente. ${ }^{55}$

No sólo la pintura, sino también el lenguaje permite ingresar en un devenir-imperceptible. Frente a las semióticas dominadas por el estrato significante, Deleuze y Guattari definen una semiótica propia del plan de consistencia, compuesta por tres elementos: verbos en infinitivo, nombres propios y artículos y pronombres indefinidos. ${ }^{56}$ Esta semiótica inmanente pone al lenguaje en un estado de variación continua, articulando un máximo de devenires con un mínimo de expresión. "Ahí es donde el lenguaje deviene intensivo, puro continuum de valores y de intensidades. [...] A ese resultado sólo se llega por sobriedad, sustracción creadora». ${ }^{57}$

Al devenir-imperceptible, al lenguaje devenido intensivo, se llega pues mediante la sobriedad de los medios. En el caso de la pintura, se trata de utilizar el trazo para introducir vacío en el lienzo; en la poesía, el poeta emplea determinados procedimientos estilísticos y gramaticales. Cheng estudia estos procedimientos en L'écriture poétique chinoise; Deleuze y Guattari los denominan «métodos pasivos» y los mencionan como ejemplo del devenirimperceptible. ${ }^{58}$ Dichos métodos comprenden técnicas como la alternancia juiciosa entre palabras «vacías» y palabras «llenas» (distinción que descansa en las oposiciones ontológicas Lleno-Vacío y Ser-No ser), la sustitución de palabras «llenas» por palabras «vacías» y también la supresión de estas últimas. Permiten al poeta introducir en la lengua

una dimensión en profundidad, justamente la del verdadero «vacío» [...] considerado por el pensamiento chino como el lugar donde las entidades vivientes o los signos se entrecruzan, se intercambian de manera no unívoca, lugar por excelencia donde se multiplica el sentido. ${ }^{59}$

Sobriedad, supresión, vacío: prácticas creativas para todo tipo de pintores y poetas. Tal parece ser el camino hacia el sueño oriental de una escritura de-

55 Cheng, F., Op. cit., p. 100, mi traducción.

56 MM, pp. 266-268.

57 MM, p. 102.

58 MM, pp. 268, 311.

59 Cheng, F., L'écriture poétique chinoise. Suivi d'une anthologie des poèmes des Tang. Paris: Éditions du Seuil, 1996, p. 38, mi traducción. 
venida inmanente. Sueño de Kerouac y de Virginia Woolf: «que la escritura fuese como la línea de un dibujo-poema chino». ${ }^{60}$

\section{Palabras finales}

Los temas y figuras expuestos en este trabajo integran una serie de «perturbadoras afinidades» entre el pensamiento de Deleuze y Guattari y la filosofía oriental, más particularmente la china. Las técnicas pictóricas y poéticas chinas, basadas en la sobriedad y el Vacío, aparecieron como llaves de acceso a un devenir-imperceptible, «modelo», a la vez ético y estético, realizado ejemplarmente por el pintor-poeta. Por otra parte, mientras que en QEF la esquiva relación entre el pensamiento por conceptos y el pensamiento por figuras es delineada sobre los contornos de un Oeste «horizontal» y un Este «verticalizado», en MM apreciamos dos series de paisajes, orientales y rizomáticos los unos, occidentales y arborizados los otros, que «desfasan» aquellas relaciones, evidenciando la compleja relación existente entre el pensamiento, los territorios y la tierra. Finalmente, la ambigüedad en el tratamiento de los hexagramas del Yijing muestra la dificultad de realizar una demarcación geo-filosófica entre conceptos, figuras, filosofía y sabiduría.

La pregunta que estas figuras deleuziano-guattarianas del Oriente ponen en juego es, entonces, fundamentalmente práctica: ¿existe una correspondencia necesaria entre las diversas formas de producción del pensamiento, su distribución geo-filosófica, y las dinámicas vitales y éticas asociadas a ellas? Ensayar una respuesta será tarea de un trabajo ulterior. Sin embargo, podemos decir por ahora que las «perturbadoras afinidades» entre Deleuze, Guattari y el Oriente evidencian un fondo de interés común: la necesidad de elaborar ontologías fuertemente relacionales y procesuales, para precisar en la inmanencia las relaciones entre formas posibles de ejercer el pensamiento y modos posibles de vivir la vida. Si Deleuze y Guattari pueden apelar al pintor-poeta chino para ilustrar su propio pensamiento, es porque comparten con él una misma inquietud: la de deshacer el cuerpo, trazar el pensamiento y atravesar la pared.

Matías Sorch es licenciado en Filosofía por la Universidad de Buenos Aires. Es becario doctoral del CONICET (Consejo Nacional de Investigaciones Científicas y Técnicas, Argentina) y doctorando en la misma universidad.

Lineas de investigación

Las relaciones entre ontología y filosofía práctica en Deleuze, Spinoza yel taoísmo filosó-

60 MM, p. 281. 
fico chino. Filosofías de la inmanencia. Deleuze y la identidad de género: perspectivas desde la lingüística crítica (Análisis Crítico del Discurso).

\section{Publicaciones recientes}

«Entre Confucio y Deleuze: el lugar de la cultura en la formación humana. Una constelación de oriente y occidente», en J. Ezcurdia (Ed.), Configuraciones formativas V. Cultura y formación, Guanajuato, México: Universidad de Guanajuato, 2011, pp. 137-164.

«East and West: some immanent thoughts on paradigmatic intersection», en Journal of Multicultural Discourses, Routledge, Vol.5, No 3, 2010, pp.271-290.

Dirección electrónica: matias.soich@gmail.com 